Marquette University

e-Publications@Marquette

$2-1-2013$

Fatigability and Recovery of Arm Muscles with Advanced Age for Dynamic and Isometric Contractions

Tejin Yoon

Marquette University, tejin.yoon@marquette.edu

Bonnie Schlinder-Delap

Marquette University, bonnie.schlinder-delap@marquette.edu

Sandra K. Hunter

Marquette University, sandra.hunter@marquette.edu

Accepted version. Experimental Gerontology, Vol. 48, No. 2 (February 2013): 259-268. DOI. (C) 2013 Elsevier. Used with permission. 


\title{
Fatigability and Recovery of Arm Muscles with Advanced Age for Dynamic and Isometric Contractions
}

\author{
Tejin Yoon \\ Exercise Science Program, Department of Physical Therapy \\ Marquette University \\ Milwaukee, WI \\ Bonnie Schlinder-Delap \\ Exercise Science Program, Department of Physical Therapy \\ Marquette University \\ Milwaukee, WI \\ Sandra K. Hunter \\ Exercise Science Program, Department of Physical Therapy \\ Marquette University \\ Milwaukee, WI
}

\begin{abstract}
This study determined whether age-related mechanisms can increase fatigue of arm muscles during maximal velocity dynamic contractions, as occurs in the lower limb. We compared elbow flexor fatigue of young $(n=10,20.8 \pm 2.7$ years $)$ and old men ( $n=16,73.8 \pm 6.1$ years) during and in recovery from a dynamic and an isometric postural fatiguing task. Each task was maintained until failure while supporting a load equivalent to $20 \%$ of maximal voluntary isometric contraction (MVIC) torque. Transcranial magnetic stimulation (TMS) was used to assess supraspinal fatigue (superimposed twitch, SIT) and muscle relaxation. Time to failure was longer for old men than young for the isometric task ( $9.5 \pm 3.1 \mathrm{vs} .17 .2 \pm 7.0 \mathrm{~min}$, $P=0.01)$ but similar for the dynamic task $(6.3 \pm 2.4 \mathrm{~min}$ vs. $6.0 \pm 2.0 \mathrm{~min}, P=0.73)$. Initial peak rate of relaxation was slower for the old men than young, and associated with a longer time to failure for both tasks $(P<0.05)$. Low initial power during elbow flexion was associated with the greatest difference (reduction) in time to failure
\end{abstract}


NOT THE PUBLISHED VERSION; this is the author's final, peer-reviewed manuscript. The published version may be accessed by following the link in the citation at the bottom of the page.

between the isometric task and dynamic task $(r=-0.54, P=0.015)$. SIT declined after both fatigue tasks similarly with age, although recovery of SIT was associated with MVIC recovery for the old (both sessions) but not the young. Biceps brachii and brachioradialis EMG activity (\%MVIC) of old men were greater than young during the dynamic fatiguing task $(P<0.05)$, but similar during the isometric task. Muscular mechanisms and greater relative muscle activity (EMG activity) explain the greater fatigue during dynamic task for the old men compared with young in elbow flexor muscles. Recovery of MVC torque however relies more on recovery of supraspinal fatigue among older men than the young men.

Keywords: time to task failure, muscle fatigue, peripheral fatigue, supraspinal fatigue, aging

\section{Introduction}

Muscle fatigue is an exercise-induced decline in maximal voluntary muscle force or power, and it develops soon after the onset of sustained physical activity (Enoka and Duchateau 2008). Agerelated changes within the neuromuscular system will impact physiological adjustments during a fatiguing task that can cause old adults to exhibit different fatigue characteristics than young (Hunter 2009). Under isometric conditions, for example, healthy old adults are less fatigable than young for lower and upper extremity muscles during both submaximal and maximal contractions (Allman and Rice 2002; Avin and Frey Law 2011; Christie et al. 2011). The mechanism for the greater fatigue resistance with age likely involves age-related slowing of the muscle reflected in a longer and slower muscle relaxation (Hunter et al. 1999; Hunter et al. 2008) due to a greater proportional area of type I fibers and slower calcium regulation (Hunter et al. 1999; Klein et al. 2003; Monemi et al. 1998). Slower contractile kinetics can enhance force during isometric tasks (Allman and Rice 2004) but when maintenance of rapid contraction velocity is required, old adults may not have the same advantage. Accordingly, the age-related loss of maximal muscle power exerted by a limb is greater than the reduction in maximal isometric strength (Metter et al. 1997) and more predictive of physical function among old adults (Reid and Fielding 2012).

Despite the relevance of dynamic contractions to daily functional tasks, the age-associated muscle fatigue during dynamic contractions is less understood than isometric contractions and has been primarily examined in lower limb muscles [e.g. (Dalton et al. 2012)]. Until recently, the findings have been disparate because some studies have

Experimental Gerontology, Vol. 48, No. 2 (February 2013): pg. 259-268. DOI. This article is (C) Elsevier and permission has been granted for this version to appear in e-Publications@Marquette. Elsevier does not grant permission for this article to be further copied/distributed or hosted elsewhere without the express permission from Elsevier. 
shown that old adults have greater fatigue (loss of muscle power or force exerted by a limb) than young during dynamic contractions (Baudry et al. 2006; Dalton et al. 2010b; McNeil and Rice 2007; Petrella et al. 2005), while others have shown similar fatigue (Callahan et al. 2009; Laforest et al. 1990; Lindstrom et al. 1997) or less fatigue in old adults than young (Lanza et al. 2004). More recent studies have clarified that the age-related fatigue of the knee extensor and ankle dorsiflexor muscles in men (Dalton et al. 2012; 2010b) and the knee extensors in women (Callahan and Kent-Braun 2011) are velocity dependent: for relatively high velocity contractions, older adults were more fatigable than young (Callahan and Kent-Braun 2011; Dalton et al. 2012; 2010b). There are however, no known studies investigating the age-related muscle fatigue during dynamic contractions in upper extremity muscles which appear to differ in age-related changes in muscle morphology and function relative to the lower extremity (Grimby et al. 1982; Hunter et al. 2000). Given that power of upper arm muscles is associated with mortality (Metter et al. 2004), and the importance of arm activity to daily tasks such as lifting grocery bags, we investigated the loss of power during a repeated contractions of upper arm muscles, and associated mechanisms.

A primary purpose of this study was to compare fatigue and fatigue-related mechanisms in young and old adults during a dynamic contraction with the elbow flexor muscles while supporting an inertial load. We hypothesized that older adults would have a briefer time to failure for repeated dynamic contractions than young adults. A second purpose was to compare fatigue in young and old adults during and after an isometric postural contraction with the elbow flexor muscles while maintaining an inertial load. A postural isometric contraction was examined because most aging studies involving isometric contractions have compared fatigue in young and old adults when the limb is restrained to a force transducer (force control) and stability of the limb is high [see (Kent-Braun 2009)]. Fatigue however is greater for both young and old adults for an isometric contraction when sustaining an inertial load (position control) compared with the force task (Griffith et al. 2010; Hunter et al. 2005; Hunter et al. 2002). Although maintaining an inertial load is a functionally relevant static task (such as maintaining loads/objects in space), there are no studies comparing fatigue elicited by a postural isometric fatiguing contraction in young and old adults for the elbow flexor muscles. We hypothesized that

Experimental Gerontology, Vol. 48, No. 2 (February 2013): pg. 259-268. DOI. This article is (C) Elsevier and permission has been granted for this version to appear in e-Publications@Marquette. Elsevier does not grant permission for this article to be further copied/distributed or hosted elsewhere without the express permission from Elsevier. 
older adults would have a greater time to failure than young adults for the sustained isometric postural contraction.

A third purpose was to determine the contribution of supraspinal fatigue (neural mechanisms) and contractile properties (muscular mechanisms) to fatigue during and in recovery from the dynamic and isometric fatiguing contractions in young and old men. Old adults can exhibit slower recovery of maximal force after isometric fatiguing contractions for some muscle groups due to decreased motoneuronal output and greater supraspinal fatigue than young (Dalton et al. 2010a; Hunter et al. 2008; Yoon et al. 2012; Yoon et al. 2008) indicating cortical drive may have greater involvement in recovery of force in old adults compared with young adults. The influence of isometric postural and dynamic fatiguing tasks on the mechanisms of recovery with age is not known.

\section{Methods}

Ten young men (18-26 years) and 16 old men (66-78 years) volunteered to participate in one or two sets of experiments that involved a fatiguing contraction with the left elbow flexor muscles. One set of experiments involved a dynamic contraction ( $n=9$ young and 16 old) and the other set an isometric postural fatiguing contraction ( $n$ $=7$ young and 14 old). Six young and 14 old men completed both set of experiments i.e. the isometric and dynamic protocols. All subjects were healthy with controlled blood pressure, no known neurological diseases and were naive to the protocol. Prior to participation, each subject provided written informed consent, and the protocol was approved by the Marquette University Institutional Review Board.

All subjects attended a familiarization session that involved a physical activity questionnaire (Kriska and Bennett 1992), habituation of the electrical-stimulation to the brachial plexus and transcranial magnetic stimulation (TMS) to the motor cortex, and practice of brief submaximal contractions, maximal voluntary isometric contractions (MVIC) and maximal voluntary concentric contractions (MVCC). Hand dominance was estimated using the Edinburgh Handedness Inventory (Oldfield 1971) with a ratio of 1 indicating complete right-handedness. The experimental sessions involved performance of an isometric fatiguing contraction (position holding) or a dynamic fatiguing

Experimental Gerontology, Vol. 48, No. 2 (February 2013): pg. 259-268. DOI. This article is (c) Elsevier and permission has been granted for this version to appear in e-Publications@Marquette. Elsevier does not grant permission for this article to be further copied/distributed or hosted elsewhere without the express permission from Elsevier. 
NOT THE PUBLISHED VERSION; this is the author's final, peer-reviewed manuscript. The published version may be accessed by following the link in the citation at the bottom of the page.

contraction for as long as possible with a load equivalent to $20 \%$ MVIC torque.

\section{Subject Set Up and Mechanical Recordings}

For both sets of experiments, each subject was seated upright in an adjustable chair with their left arm slightly abducted. Their elbow was resting comfortably on a padded elbow support and the elbow joint was flexed to 90 degrees so that the forearm was horizontal to the ground. The subject's shoulders were restrained by two nylon straps to minimize shoulder movement. The hand and forearm were placed in a modified rigid wrist-hand-thumb orthosis (Orthomerica, Newport Beach, CA) midway between pronation and supination and the force was directed upward when the elbow flexor muscles were activated. The forces exerted by the wrist in the vertical directions (during MVIC) were measured with a force transducer (Force-Moment Sensor, JR-3, Woodland, CA) that was mounted on a custom designed, adjustable support. The orthosis was fixed to the force transducer. For the dynamic contraction and postural isometric contraction, a potentiometer (Alpha Product Inc, 16mm Rotary type, Oxnard, CA) was mounted to the axis of rotation of the elbow support. The angles detected by the potentiometer and the forces detected by the force transducer were recorded online by using a Power 1401 A-D converter and Spike 2 software [Cambridge Electronics Design (CED), Cambridge, UK]. The force and position signals were digitized at 500 samples/s and displayed on a 19-inch monitor located $1.5 \mathrm{~m}$ in front of the subject.

\section{Electrical Recordings}

Electromyography (EMG) signals were recorded with a bipolar configuration using surface electrodes ( $\mathrm{Ag}-\mathrm{AgCl}$, 8-mm diameter; 16 $\mathrm{mm}$ between electrodes) that were placed over the biceps brachii, brachioradialis, and triceps brachii muscles according to recommended placements (Hermens et al. 2000). Reference electrodes were placed on the lateral epicondyle of the elbow. The EMG signals were amplified $(100 \times)$ and band-pass filtered $(13-1000 \mathrm{~Hz})$ with Coulbourn modules (Coulbourn Instruments, Allentown, PA). The signal was displayed on

Experimental Gerontology, Vol. 48, No. 2 (February 2013): pg. 259-268. DOI. This article is (c) Elsevier and permission has been granted for this version to appear in e-Publications@Marquette. Elsevier does not grant permission for this article to be further copied/distributed or hosted elsewhere without the express permission from Elsevier. 
NOT THE PUBLISHED VERSION; this is the author's final, peer-reviewed manuscript. The published version may be accessed by following the link in the citation at the bottom of the page.

an oscilloscope and recorded online via a Power 1401 A-D converter (CED). The EMG signals were digitized at 2000 samples/s.

\section{Stimulation}

Subjects were stimulated at the brachial plexus with electrical stimulation and at the motor cortex with TMS.

\section{Brachial Plexus Stimulation}

The brachial plexus was electrically stimulated to produce a maximal compound muscle action potential (maximal $M$ wave: $M_{\max }$ ) of the biceps brachii, brachioradialis and triceps brachii muscles. A constant-current stimulator (model DS7AH, Digitimer, Welwyn Garden City, Hertforshire, UK) was used to deliver single stimuli (100 $\mu \mathrm{s}$ duration) to the brachial plexus. A cathode was placed in the supraclavicular fossa and an anode on the acromion. The stimulation intensity was determined by increasing the current until the peak-topeak $M$ wave amplitude plateaued. The stimulation intensity ranged between 120 and $300 \mathrm{~mA}$ and once this intensity was determined, this level of stimulation was used for the remainder of the protocol.

\section{Motor Cortex Stimulation}

TMS stimulation was delivered via a round coil $(13.5-\mathrm{cm}$ outside diameter) over the vertex (Magstim 200, Magstim, Whitland, UK) to evoke motor-evoked potentials (MEPs) from the biceps brachii, brachioradialis and triceps brachii muscles. The vertex of the motor cortex was identified and the scalp marked to ensure repeatability of coil placement throughout the protocol. The right cerebral hemisphere was stimulated by the direction of the current flow in the coil to preferentially activate the left limb. A single pulse was delivered over the motor cortex at an intensity that produced a large MEP in the agonist biceps brachii muscle (minimum amplitude of $50 \%$ of $M_{\max }$ during a brief MVIC of the elbow flexor muscles) and small MEP of the triceps brachii (Todd et al. 2004).

Experimental Gerontology, Vol. 48, No. 2 (February 2013): pg. 259-268. DOI. This article is (c) Elsevier and permission has been granted for this version to appear in e-Publications@Marquette. Elsevier does not grant permission for this article to be further copied/distributed or hosted elsewhere without the express permission from Elsevier. 


\section{Experimental Protocol}

Optimal levels of stimulation intensities to the motor cortex and brachial plexus were determined and these levels remained constant throughout the rest of the protocol. All procedures thereafter were as follows as indicated in Figure 1:

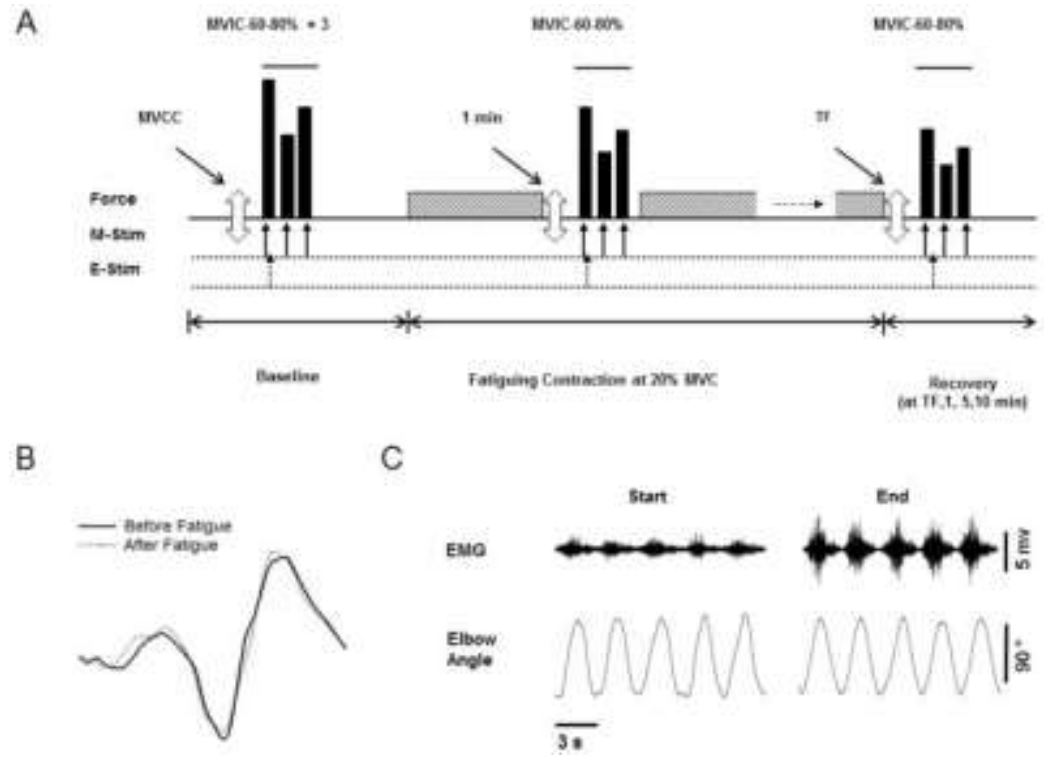

Figure 1. Experimental protocol

A. The top panel shows the order of force and power tasks performed by each subject with the elbow flexor muscles. Three maximal voluntary concentric contractions (MVCC, open arrow) were followed by sets of 3 brief contractions shown in solid bars [maximal voluntary isometric contractions (MVIC), $60 \%$ and $80 \%$ MVIC] before (baseline), during (at $1 \mathrm{~min}$ ) and in recovery from the fatiguing contraction. Recovery measures occurred at task failure (TF) and at 1,5 and 10 min post fatigue (recovery). The fatiguing contraction ( $20 \%$ of MVIC, either dynamic or isometric) is symbolized with the hatched rectangle, and was performed until task failure by each subject. The second and third panel shows with the arrows, when the magnetic stimulation (Mstim) and electrical stimulation (E-Stim) were applied during each contraction. Please note the Figure $1 \mathrm{~A}$ is not to scale. B-C. Representative data for an old male subject. B. Motor evoked potential (MEP) during MVIC contraction performed before (solid line) and after (dotted line) the dynamic fatiguing contraction. C. Shown are the interference EMG and elbow angle (provided as feedback) for 5 contractions at the start and end of dynamic fatiguing contraction.

Maximal Voluntary Isometric Contractions (MVIC) Two MVICs of the elbow extensor muscles separated by 1 minute of rest were performed so that peak EMG values could be obtained to normalize the triceps EMG activity during the fatiguing contraction. Four sets of brief

Experimental Gerontology, Vol. 48, No. 2 (February 2013): pg. 259-268. DOI. This article is (C) Elsevier and permission has been granted for this version to appear in e-Publications@Marquette. Elsevier does not grant permission for this article to be further copied/distributed or hosted elsewhere without the express permission from Elsevier. 
NOT THE PUBLISHED VERSION; this is the author's final, peer-reviewed manuscript. The published version may be accessed by following the link in the citation at the bottom of the page.

contractions ( $2-3 \mathrm{~s}$ ) with the elbow flexor muscles were performed and separated by 2 minutes of rest to minimize fatigue. Each set involved performance of a MVIC followed by contractions at $60 \%$ and $80 \%$ MVIC. Within each set, the start of each contraction was separated by $\sim 4 \mathrm{~s}$. If peak forces from two of the four MVIC's trials were not within $5 \%$ of each other, additional trials were performed until this was accomplished. TMS was delivered during each contraction and brachial plexus stimulation was delivered only during the MVICs. Sets of contractions (MVIC, $60 \%$ and $80 \%$ of MVIC) along with the above described stimulation were also performed during the fatiguing contraction at 1 minute, and then several times during 10 minutes of recovery (see below for recovery times).

Maximal Voluntary Concentric Contraction (MVCC): Each subject was required to perform two consecutive concentric (shortening) contractions with the elbow flexor muscles between an elbow joint angle of $45^{\circ}$ to $135^{\circ}$ as fast as possible. Each subject lifted a weight equal to $20 \%$ of MVIC torque. During the remainder of the protocol, the two MVCCs were performed before each MVIC. The fastest of the two contractions was taken as the MVCC.

Fatiguing Contraction: A fatiguing contraction was performed with the elbow flexor muscles in each session with a weight equal to $20 \%$ of MVIC torque until task failure. For the isometric postural task, each subject was required to maintain the weight at an elbow angle of $90^{\circ}$. The fatiguing contraction was terminated when an automated computer program (Spike 2, CED) indicated that the force had declined by $10 \%$ of the target value for 2.5 out of 5 consecutive seconds. This time was recorded as the time to task failure. For the dynamic task, each subject moved the weight through a $90^{\circ}$ range of motion $\left(45^{\circ}\right.$ to $\left.135^{\circ}\right)$ at 1 cycle every 3 seconds. Visual feedback for joint angle displayed the upper and lower limits of range of motion on a 19-in. monitor located $1.5 \mathrm{~m}$ in front of the subject. A metronome was used to indicate the start of each 3-second cycle which began with the subject lifting the inertial load (concentric or shortening phase) followed by the subject lowering the inertial load (eccentric or lengthening phase) to the start position. Each subject was verbally encouraged during the both fatiguing tasks. The dynamic fatiguing task was terminated when an automated computer program (Spike 2, CED) indicated that either one of the following criteria could no longer

Experimental Gerontology, Vol. 48, No. 2 (February 2013): pg. 259-268. DOI. This article is (C) Elsevier and permission has been granted for this version to appear in e-Publications@Marquette. Elsevier does not grant permission for this article to be further copied/distributed or hosted elsewhere without the express permission from Elsevier. 
NOT THE PUBLISHED VERSION; this is the author's final, peer-reviewed manuscript. The published version may be accessed by following the link in the citation at the bottom of the page.

be achieved for 2 out of 3 contractions: (1) a range of motion between 45 and 135 deg; or (2) one dynamic contraction cycle within 3 seconds. This duration of the task was recorded as the time to task failure.

Recovery Measures: Sets of MVCC followed by MVIC force and submaximal contractions ( $60 \%$ and $80 \% \mathrm{MVC}$ ) were performed during recovery at the following times: immediately upon task failure, and at 1 minute, 5 minutes and 10 minutes after termination of the fatiguing contraction.

\section{Data Analysis}

The MVIC force was quantified as the average value over a 0.5 -s interval that was centered about the peak of the MVIC. The torque for the MVIC and submaximal contractions was calculated as the product of force and the distance between the elbow joint and the point at which the wrist was attached to the force transducer. The average contraction speed for MVCC was quantified as the average angular speed for concentric (shortening) phase (45 to $\left.135^{\circ}\right)$. The MVCC with the greatest velocity of the two consecutive MVCCs performed on each occasion was taken for analysis. The power was calculated as the product of speed and the force for the $20 \%$ MVIC.

The maximal EMG activity for each muscle was determined as the Root Mean Square (RMS) value over a 0.5-s interval about the same interval of the MVIC torque measurement. The maximal EMG value for the biceps brachii, brachioradialis and triceps brachii was used to normalize the RMS EMG values recorded during the fatiguing contraction for each respective muscle. The RMS of the EMG signal of the elbow flexor muscles and triceps brachii muscles were quantified during the fatiguing contraction at the following time intervals: for isometric task, the first and last $15 \mathrm{~s}$ of task duration, and $45 \mathrm{~s}$ to 1 min; for dynamic task, the entire cycle for the first 5 contractions of the beginning of the task, and the last 5 contractions of the 1 min and task failure. For the dynamic task, the EMG analysis was repeated but included the elbow flexion phase (also often referred to as the lifting, concentric or shortening phase) only for each of the 5 contractions previously analyzed. Coactivation of the EMG activity was calculated as the triceps brachii (TB) relative to the average of the biceps brachii

Experimental Gerontology, Vol. 48, No. 2 (February 2013): pg. 259-268. DOI. This article is (C) Elsevier and permission has been granted for this version to appear in e-Publications@Marquette. Elsevier does not grant permission for this article to be further copied/distributed or hosted elsewhere without the express permission from Elsevier. 
(BB) and brachioradialis (BR) muscles so that Coactivation $(\%)=100$ $\times \mathrm{TB} /($ average of $\mathrm{BB}$ and $\mathrm{BR})$.

The amplitude of the superimposed twitch (SIT) elicited by TMS is reported as a percentage of the voluntary torque measured immediately prior to TMS during the MVIC i.e. SIT $(\%)=100 \times$ SIT/(SIT + MVIC) (Gandevia et al. 1996). The SIT amplitude was also used to calculate voluntary activation for the MVIC prior to the fatiguing contraction (Todd et al. 2003). Voluntary activation was quantified by expressing the amplitude of the superimposed twitch (elicited by TMS) as a fraction of the estimated amplitude of the response evoked by the same stimulus at rest (estimated resting twitch). Because motor cortical and spinal cord excitability increase with activity (Hess et al. 1986) the amplitude of the resting twitch was estimated (eRT) rather than measured directly (Todd et al. 2003). During four brief maximal and submaximal contractions (60\% MVIC and $80 \%$ MVIC) TMS was elicited and the resting twitch was estimated by extrapolation of the linear relation between the amplitude of the superimposed twitch and voluntary torque. One regression analysis was performed for each set of brief contractions. The $y$-intercept was taken as the estimated amplitude of the resting twitch evoked by TMS. The amplitude of the estimated resting twitch can be accurately determined from three data points in fresh or fatigued muscle when the contractions are greater than 50\% MVC (Todd et al. 2003). For the control contractions, voluntary activation (\%) was calculated as a percentage measured by cortical stimulation [(1-SIT/eRT) $\times 100]$ (Todd et al. 2003). Data points were included for subjects when the regression of the estimated twitch was $r>0.9$ (Hunter et al. 2008). Because this criteria was not met for many of the contractions during and in recovery from fatigue (due to rapidly changing fatigue state between brief contractions) only the voluntary activation during the control trials is reported.

Contractile properties of the elbow flexor muscles were also assessed including the amplitude of the estimated resting twitch and peak relaxation rates. The peak rate of relaxation was determined during each MVIC by calculating the steepest falling of the torque during the EMG silence immediately following TMS (Todd et al. 2007). This was determined as the highest negative derivative of the torque for an interval of $10 \mathrm{~ms}$ between two cursors placed either side of the

Experimental Gerontology, Vol. 48, No. 2 (February 2013): pg. 259-268. DOI. This article is (C) Elsevier and permission has been granted for this version to appear in e-Publications@Marquette. Elsevier does not grant permission for this article to be further copied/distributed or hosted elsewhere without the express permission from Elsevier. 
fall in torque during the silent period. The steepest rate of torque decline was normalized to the total torque (MVIC plus superimposed twitch) prior to the silent period (Todd et al. 2007).

The amplitude and area of MEPs and $M$ wave were measured between two cursors placed at the start and end of the waveform for the biceps brachii muscles. Because MEP amplitude and area showed similar changes, only MEP amplitude is reported. $M$ waves were elicited after each MEP, so the MEP could be normalized to the ongoing $M$ wave amplitude. Voluntary torque was quantified by calculation of the mean torque over a 100 ms period immediately prior to TMS.

\section{Statistical Analysis}

Data are reported as means \pm SD within the text and displayed as means \pm SEM in the figures. Univariate analyses were used to compare physical characteristics, physical activity levels, time to task failure, baseline control variables including MVIC, SIT, voluntary activation, peak relaxation rate of muscle fibers, and MEP amplitude in young and old adults. Two-way ANOVAs with repeated measures (age as a fixed factor) were used to compare the young and old men across time separately for the two protocols. Separate two-way repeated ANOVAs were used to compare variables for the fatiguing contraction (baseline, $1 \mathrm{~min}$ and at time to failure) and recovery (time to failure and recovery at $1 \mathrm{~min}, 5 \mathrm{~min}, 10 \mathrm{~min}$ ). The variables include MVIC torque, average speed and power during the MVCC with the $20 \%$ load, SIT, MEP amplitude, and peak relaxation rate of muscle fibers. Twoway repeated-measure ANOVAs were performed with the 1-min data excluded (baseline and time to failure) but the statistical significance of the results did not change between the two sets of analyses for fatigue so the data that included the 1-min data were reported in the text and graphs. The strength of an association is reported as the squared Pearson product-moment correlation coefficient $\left(r^{2}\right)$. A significance level of $P<0.05$ was used to identify statistical significance.

Experimental Gerontology, Vol. 48, No. 2 (February 2013): pg. 259-268. DOI. This article is (C Elsevier and permission has been granted for this version to appear in e-Publications@Marquette. Elsevier does not grant permission for this article to be further copied/distributed or hosted elsewhere without the express permission from Elsevier. 
NOT THE PUBLISHED VERSION; this is the author's final, peer-reviewed manuscript. The published version may be accessed by following the link in the citation at the bottom of the page.

\section{Results}

Young adults and old men were similar in height, body mass, estimated physical activity levels and handedness (see Table 1 for subject characteristics).

\begin{tabular}{|c|c|c|c|c|}
\hline Variable & Enit & Voung $(x=10$ ) & $\operatorname{cad}(\mathrm{u}=16)$ & Evalise \\
\hline Age & grass: & $20.8 \pm 2.7$ & $23.5 \pm 6.1$ & $\infty 0001$ \\
\hline Heght: & com & $37 \pm 5.2$ & $176 \pm 59$ & 0860 \\
\hline Wright: & $\mathrm{kg}$ & $773+12$ & $56.4+12$ & $0 \mathrm{cos} 4$ \\
\hline Harritaloes & sin $\{0-1\}$ & $065 \pm 0.3$ & $0.69 \pm 0.3$ & 0.730 \\
\hline mo & MET h/WK & $32.9 \pm 24$ & $41.7 \pm 49$ & $0.60 \mathrm{E}$ \\
\hline MWE torpe & $\mathrm{Nm}$ & $603 \pm 87$ & $5: 5 \pm 10$ & 0087 \\
\hline Speed daring Mvec & $\operatorname{deg}$ 's & $387 . \pm 23$ & $319_{ \pm} 66 \mathrm{i}$ & 0.211 \\
\hline Prove daring Mave & w & $898 \pm 18$ & $53.9 \pm 20$ & 6003 \\
\hline Wotuntary aciticion (cot imi mean ) & 3 & $84.9 \pm \frac{25}{5}$ & $55.2 \pm 112$ & 6946 \\
\hline 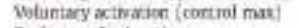 & 3 & $91,8 \pm 3.1$ & $\$ .2 \pm 78$ & 0.381 \\
\hline Prak cate of retasurion & $s^{-1}$ & $122 \pm 19$ & $10.6 \pm 1.6$ & $\cos 2$ \\
\hline St-wret anplitude (S/hes] & $\mathrm{mv}$ & $22.4+43$ & $19.0+5.2$ & 6.13 \\
\hline Nonendimf MEP amplitude & $3 \mathrm{~s} / \mathrm{nm}$ & $969 \pm 19$ & $57.4 \pm \pi 1$ & 0948 \\
\hline
\end{tabular}

\section{Baseline Measures}

There was no difference between the two experimental sessions for initial MVIC, maximal power, peak rates of relaxation, SIT, maximal $M$ waves and MEP amplitude $(P>0.05)$. Data was pooled (averaged) for the baseline (control) data from the two sessions to determine age differences and these are summarized in Table 1. Physical characteristics and activity levels were similar for the young and old men. Old men were $14.6 \%$ weaker (MVIC) and $28.8 \%$ less powerful than young men prior to the start of each fatiguing contraction $(P<$ 0.05 , Table 1 ). Initial peak rates of relaxation (during control MVICs) were $13.1 \%$ (slower) in the older men compared with the young (Table 1). Initial peak rates of relaxation were associated with initial power $\left(r=-0.40, r^{2}=0.16, P=0.006\right)$ and MVIC force $\left(r=-0.49, r^{2}\right.$ $=0.24, P=0.001)$, so that those men with a faster relaxing muscle were stronger and more powerful.

Superimposed twitch (SIT) amplitude and voluntary activation elicited during the MVIC was similar in young and old men prior to the fatiguing contractions (Table 1 ). The compound muscle action potential ( $M$ wave peak-to-peak amplitude, $M_{\max }$ ) and MEP amplitude of biceps brachii elicited during control MVICs were also similar for the young and old adults (Table 1 ).

Experimental Gerontology, Vol. 48, No. 2 (February 2013): pg. 259-268. DOI. This article is (c) Elsevier and permission has been granted for this version to appear in e-Publications@Marquette. Elsevier does not grant permission for this article to be further copied/distributed or hosted elsewhere without the express permission from Elsevier. 
NOT THE PUBLISHED VERSION; this is the author's final, peer-reviewed manuscript. The published version may be accessed by following the link in the citation at the bottom of the page.

\section{Fatigue and Recovery}

Time to Task Failure: For the isometric postural contraction the time to task failure was briefer for the young adults than the old adults $\left(9.5 \pm 3.1 \mathrm{~min}\right.$ vs. $17.2 \pm 7.0 \mathrm{~min}$, respectively, $F_{(1,19)}=7.52, P=$ $0.01)$. The time to task failure for the dynamic task however was similar for the young and old adults $(6.3 \pm 2.4 \mathrm{~min}$ vs. $6.0 \pm 2.0 \mathrm{~min}$, respectively, $\left.F_{(1,23)}=0.12, P=0.73\right)$. See Fig. 2 A.

A

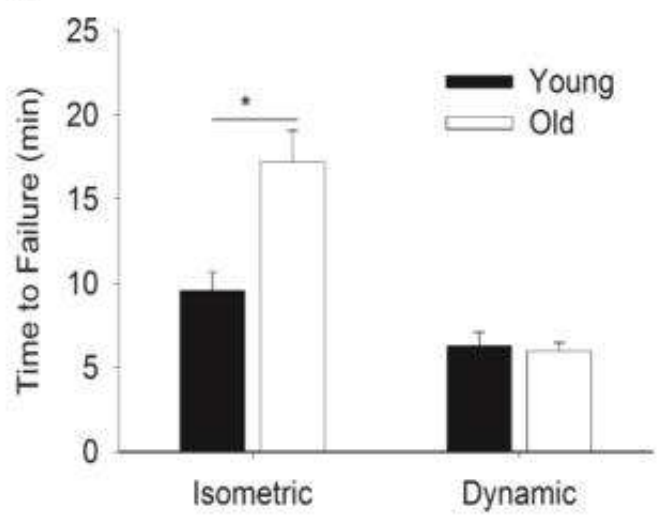

C

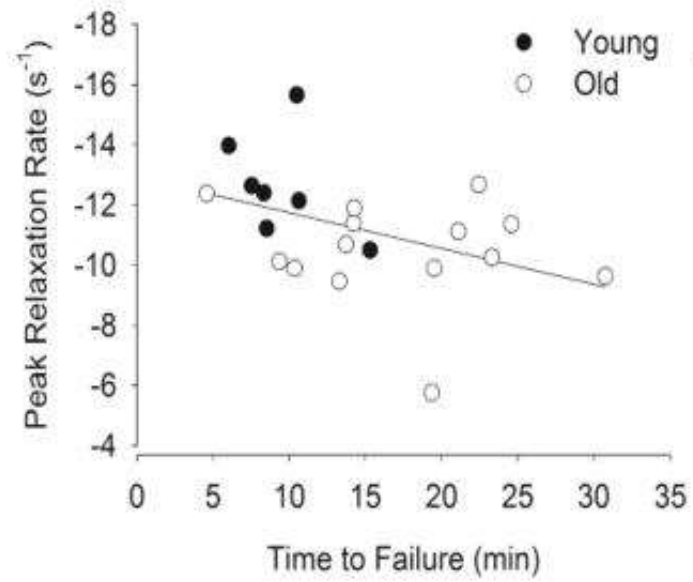

B
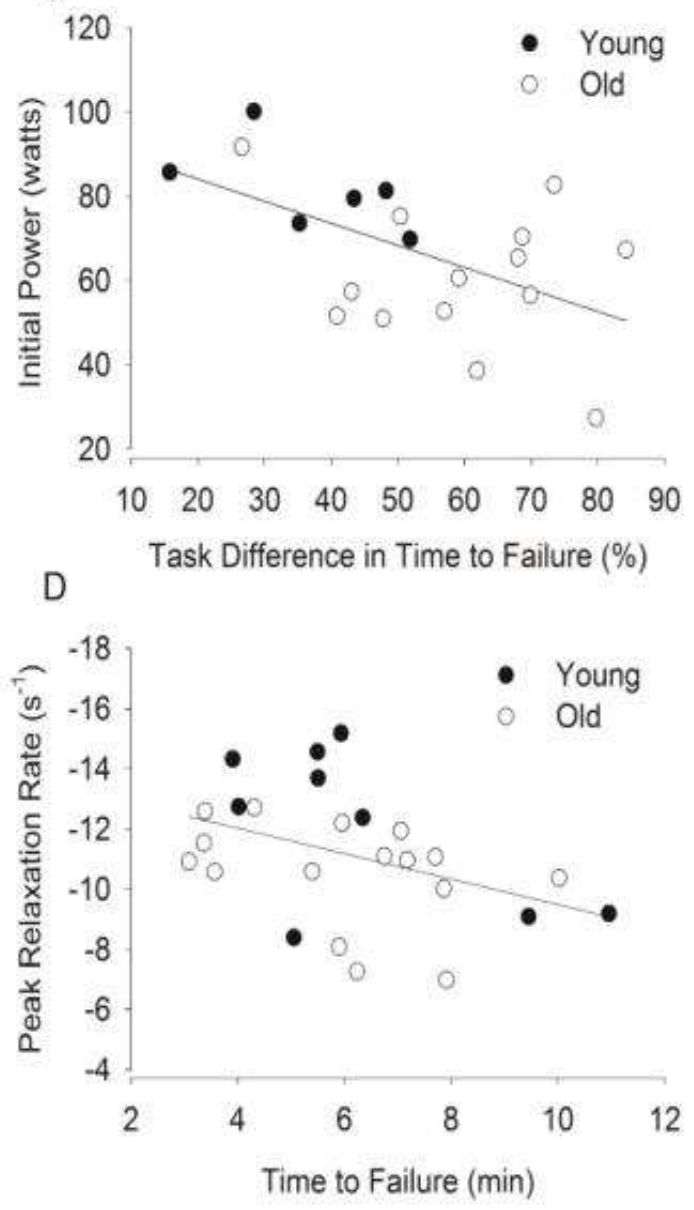

Figure 2. Time to task failure and associations with initial power and peak rates of relaxation of muscle

A. Time to task failure of young and old men for the dynamic and isometric postural contractions. Shown are the means $( \pm$ SEM). * denotes an age difference for the isometric task $(P<0.05)$. B. The difference in the time to failure (between the isometric and the dynamic contraction for those subjects who performed both protocols, $n=6$ young and 14 old men) was associated with the peak power during initial maximal velocity concentric contractions performed prior to the fatiguing

Experimental Gerontology, Vol. 48, No. 2 (February 2013): pg. 259-268. DOI. This article is (C) Elsevier and permission has been granted for this version to appear in e-Publications@Marquette. Elsevier does not grant permission for this article to be further copied/distributed or hosted elsewhere without the express permission from Elsevier. 
contractions $\left(r=-0.54, r^{2}=0.29, P=0.015\right)$. C-D. Time to task failure was associated with the peak rate of relaxation for the isometric postural contraction $(\mathrm{C}, \mathrm{r}$ $=-0.43, r^{2}=0.19, n=7$ young and 14 old men) and dynamic contraction $(D, r=-$ $0.44, r^{2}=0.20, n=9$ young and 16 old men). A faster rate of relaxation was associated with a briefer time to failure for both tasks $(P<0.05)$. Note that the $y$-axis for panels $C$ and $D$ is inverted. Larger negative numbers indicate more rapid relaxation.

There were several variables at baseline that were associated with the time to failure of the tasks. The initial peak rate of relaxation (during control MVIC) correlated with the time to task failure for both the isometric postural contraction $\left(r=-0.43, r^{2}=0.19, P=0.049\right.$, Fig. 2C) and dynamic contraction ( $r=-0.44, r^{2}=0.20, P=0.025$, Fig. 2D). For both fatiguing contractions, those individuals who had a faster peak rate of relaxation had a briefer time to failure.

A difference in the time to task failure between dynamic and isometric tasks, for those subjects who completed both experiments ( 6 young and 14 old men), was associated with the baseline power during elbow flexion (averaged over the shortening phase). Those men who had lower initial power had the greatest difference (reduction) in time to task failure from the isometric task to dynamic task $\left(r=-0.54, r^{2}=\right.$ 0.29, $P=0.015$, Fig. 2B).

\section{Maximal Strength (MVIC)}

Isometric Task: MVIC torque decreased immediately from control values to that after the fatiguing contraction $(P<0.001)$. The young men had similar relative declines in MVIC torque compared with the old men (Age $\times$ Fatigue interaction, $F_{(2,18)}=0.28, P=0.76,17.4$ $\pm 8.2 \%$ vs $27.1 \pm 15.3 \%$, respectively). See Fig. 3A. During recovery, MVIC torque increased similarly for the young and old adults (Fatigue effect, $F_{(3,17)}=8.54, P<0.001$; Age $\times$ Recovery interaction, $F_{(3,21)}=$ $2.29, P=0.11$ ) so that the relative MVIC torque was similar for both groups at 10 minutes of recovery $(89.2 \pm 6.0$ vs. $87.3 \pm 9.9 \%$ of the control value respectively, $\left.F_{(1,19)}=0.22, P=0.64\right)$.

Experimental Gerontology, Vol. 48, No. 2 (February 2013): pg. 259-268. DOI. This article is (C) Elsevier and permission has been granted for this version to appear in e-Publications@Marquette. Elsevier does not grant permission for this article to be further copied/distributed or hosted elsewhere without the express permission from Elsevier. 

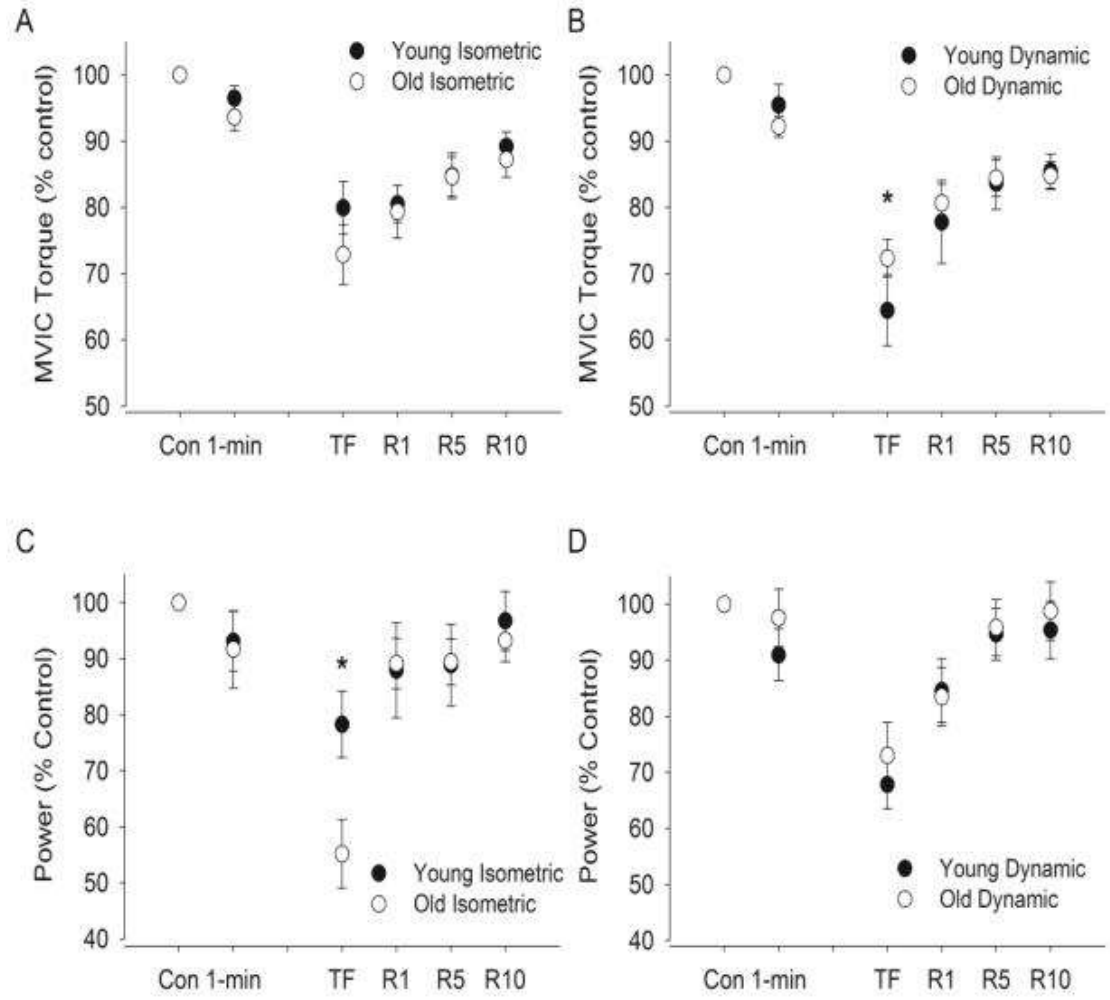

Figure 3. Maximal voluntary contraction (MVIC) and power during the maximal voluntary concentric contractions

For the MVIC (A-B) and average power (C-D) values are expressed relative to control values obtained during baseline contractions (\% of control) of the isometric postural ( $A$ and $C, n=7$ young and 14 old men) and dynamic contractions ( $B$ and $D, n=9$ young and 16 old men). Shown are the mean ( \pm SEM) during control trials before the fatiguing contraction (Con), at 1 min, immediately after the fatiguing contraction (TF), and during recovery at $1 \mathrm{~min}$ (R1), $5 \mathrm{~min}$ (R5), and $10 \mathrm{~min}$ (R10). Values are expressed as means $( \pm \mathrm{SEM})$. [ $*$ indicates an age difference at task failure at $\mathrm{P}<$ 0.05 ]. Note that $1 \mathrm{~min}$ is equivalent in time to $10.5 \%$ and $5.8 \%$ of time to failure in young and old men respectively for isometric task and $15.9 \%$ and $16.9 \%$ respectively for the dynamic task.

Dynamic Task MVIC torque decreased immediately after the fatiguing contraction from control values $(P<0.001$, Fig. 3B). The young men had relatively greater reductions than the old men in maximal torque immediately after the dynamic task (Age $\times$ Fatigue interaction, $\mathrm{F}_{(2,22)}=4.0, P=0.033,35.5 \pm 16.1$ vs. $27.7 \pm 11.3 \%$, respectively). During recovery, MVIC torque increased (Fatigue effect, $\left.F_{(3,69)}=30.6, P<0.001\right)$, but the young men had a greater relative increase compared with the old men (Age $\times$ Recovery interaction, $F_{(3,}$ ${ }_{69)}=2.91, P=0.040$ ) because they were recovering from lower relative values. Hence, by 10 minutes of recovery, the relative MVIC

Experimental Gerontology, Vol. 48, No. 2 (February 2013): pg. 259-268. DOI. This article is (C) Elsevier and permission has been granted for this version to appear in e-Publications@Marquette. Elsevier does not grant permission for this article to be further copied/distributed or hosted elsewhere without the express permission from Elsevier. 
torque was similar for both the young and old men $(85.5 \pm 7.8$ vs. $84.8 \pm 8.4 \%$ of the control value respectively, $F_{(1,23)}=0.04, P=$ $0.85)$.

\section{Power During Elbow Flexion}

Isometric Task Elbow flexion power (during maximal elbow flexion averaged over the shortening phase) decreased during and after the isometric fatiguing contraction from control values for the young and old adults $\left(F_{(2,18)}=22.7, P<0.001\right)$. The relative decline by task failure was less for the young men ( $78.3 \pm 15.6 \%$ of control) than the old men (55.2 $\pm 22.7 \%$ of control, $P=0.026$, Fig. $3 C$ ). During recovery, average power increased for the young and old men $\left(F_{(3,17)}=9.63, P<0.001\right)$, and was similar for both groups at 10 minutes of recovery $(96.8 \pm 14.0$ vs. $93.3 \pm 14.3 \%$ of the control value respectively, $\left.F_{(1,19)}=0.28, P=0.60\right)$.

Dynamic Task For the dynamic task, average power decreased during and after the fatiguing contraction from control values for the young and old adults $\left(F_{(2,22)}=26.9, P<0.001\right)$ and the relative decline was similar for both age groups $\left(F_{(2,22)}=1.30, P=0.29\right)$. Average power increased for the young and old adults during recovery $\left(F_{(3,21)}=20.0, P<0.001\right)$, and was similar for both groups by 10 minutes of recovery ( $95.4 \pm 15.4$ vs. $98.8 \pm 20.9 \%$ of the control value, respectively $F_{(1,23)}=0.18, P=0.67$, Fig. 3D).

\section{Peak Rate of Relaxation}

Isometric Task Peak rates of relaxation did not change from initial control values during the fatiguing contraction and at task failure (time effect, $F_{(2,18)}=3.10, P=0.07$, Fig. 4A), but increased for both young and old adults during recovery (time effect, $F_{(3,17)}=9.38, P<$ $0.001)$. There was no interaction between age and time during fatigue $(P=0.37)$ and recovery $(P=0.26)$.

Experimental Gerontology, Vol. 48, No. 2 (February 2013): pg. 259-268. DOI. This article is (C) Elsevier and permission has been granted for this version to appear in e-Publications@Marquette. Elsevier does not grant permission for this article to be further copied/distributed or hosted elsewhere without the express permission from Elsevier. 
NOT THE PUBLISHED VERSION; this is the author's final, peer-reviewed manuscript. The published version may be accessed by following the link in the citation at the bottom of the page.

A

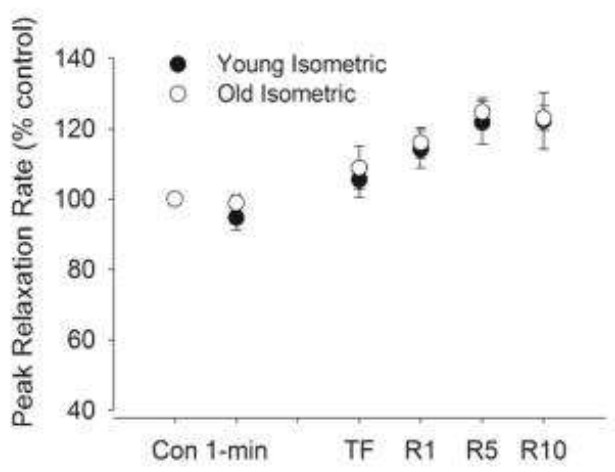

C

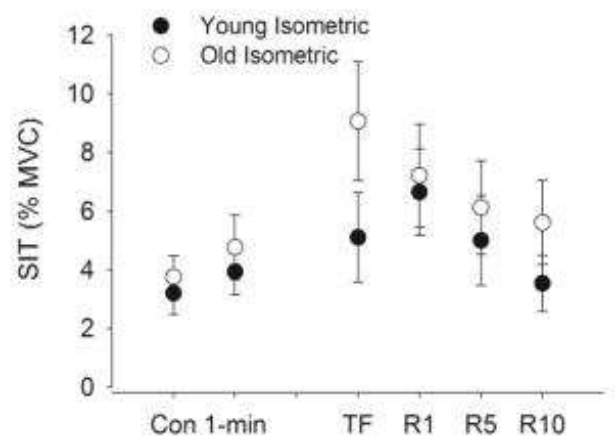

B

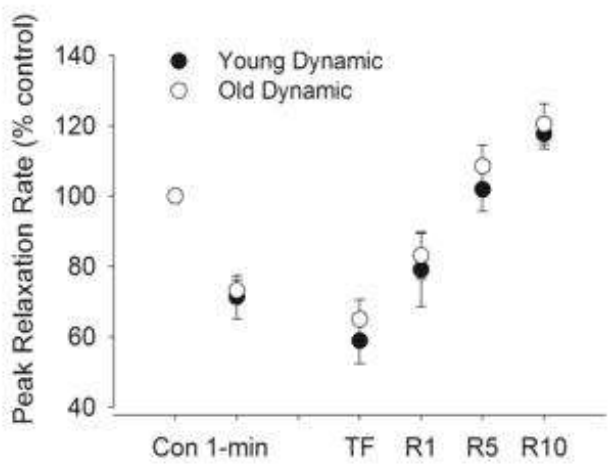

D

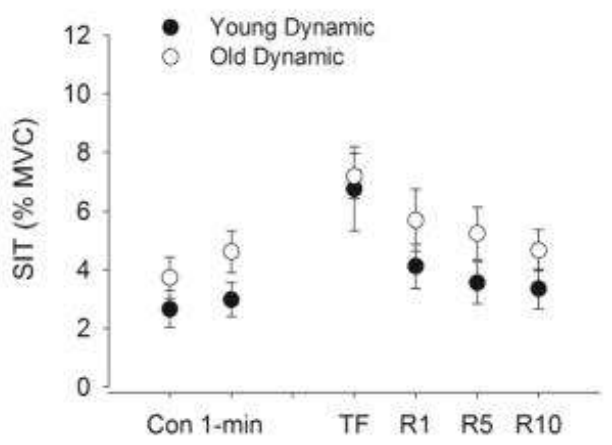

Figure 4. Superimposed twitch (SIT) amplitude and peak relaxation rate of muscle fibers elicited from cortical stimulation during MVICs

Shown are the mean ( \pm SEM) in the young and old men during the isometric ( $n=7$ young and 14 old men) and dynamic protocol ( $n=9$ young and 16 old men) A-B. The peak relaxation rate of muscle fibers shown as a percent of control at $1 \mathrm{~min}$, immediately after the fatiguing contraction (TF), and during recovery at $1 \mathrm{~min}(\mathrm{R} 1), 5$ min (R5), and $10 \mathrm{~min}$ (R10). C-D. SIT is expressed relative to the MVIC torque (\%) and shown for control trials before the fatiguing contraction (Con), at $1 \mathrm{~min}$, immediately after the fatiguing contraction (TF), and during recovery at $1 \mathrm{~min}$ (R1), 5 $\min$ (R5), and $10 \mathrm{~min}$ (R10). Note that $1 \mathrm{~min}$ is equivalent in time to $10.5 \%$ and $5.8 \%$ of time to failure in young and old men respectively for isometric task and $15.9 \%$ and $16.9 \%$ respectively for the dynamic task.

Dynamic Task Peak rates of relaxation decreased from initial control values during the fatiguing contraction and at task failure (time effect, $F_{(2,22)}=53.1, P<0.001$, Fig. 4B) by $38.9 \%$ for the young and $34.4 \%$ for the old men. During recovery, peak rates of relaxation increased for both young and old adults (time effect, $F_{(3,21)}=87.6, P$ $<0.001)$. There was no interaction between age and time during fatigue $(P=0.49)$ and recovery $(P=0.12)$.

Experimental Gerontology, Vol. 48, No. 2 (February 2013): pg. 259-268. DOI. This article is C) Elsevier and permission has been granted for this version to appear in e-Publications@Marquette. Elsevier does not grant permission for this article to be further copied/distributed or hosted elsewhere without the express permission from Elsevier. 
Superimposed Twitch (SIT)

Isometric Task SIT increased from initial control values during the fatiguing contraction and at task failure $\left(F_{(2,18)}=5.59, P=0.013\right)$ and then decreased for both young and old adults during recovery $\left(F_{(3,}\right.$ 17) $=4.46, P=0.017$, Fig. $4 \mathrm{C})$. There was no age difference in SIT with fatigue $\left(F_{(1,19)}=1.02, P=0.33\right)$ and during recovery $\left(F_{(1,19)}=\right.$ $0.63, P=0.44)$ and no interaction between age and time during fatigue $(P=0.39)$ and recovery $(P=0.33)$.

Dynamic Task SIT increased from initial control values during the fatiguing contraction and at task failure $\left(F_{(2,22)}=10.3, P=0.001\right)$ and then decreased for both young and old adults during recovery $\left(F_{(3,}\right.$ 21) $=5.05, P<0.01$, Fig. 4D). There was no age difference in SIT with fatigue $\left(F_{(1,23)}=1.32, P=0.26\right)$ and during recovery $\left(F_{(1,23)}=1.27, P=\right.$ $0.271)$ and no interaction between age and time during fatigue $(P=$ $0.55)$ and recovery $(P=0.86)$.

There was however, an association between the recovery of MVIC torque and the recovery of SIT in old men for the isometric ( $r=$ $\left.-0.44, r^{2}=0.19, P=0.004\right)$ and dynamic contraction $\left(r=-0.49, r^{2}=\right.$ $0.24, P<0.001)$. The correlation was not significant for young men in recovery from the isometric task $(P=0.57)$ and dynamic task $(P=$ $0.17)$.

\section{M-waves and Motor Evoked Potentials}

Isometric Task M wave amplitude did not change during or in recovery from the isometric postural fatiguing contraction. MEP amplitude (normalized to the $M_{\max }$ ) of biceps brachii did not change at the end of the fatiguing contraction (time effect, $F_{(2,18)}=3.17, P=$ $0.07)$ or by the end of 10 minutes of recovery $\left(F_{(3,21)}=2.02, P=\right.$ $0.14)$.

Dynamic Task M wave amplitude did not change during or in recovery from the dynamic fatiguing contraction. MEP amplitude (normalized to the $M_{\max }$ ) of biceps brachii did not change at the end of the fatiguing contraction (time effect, $F_{(2,22)}=2.5, P=0.11$ ) or by the end of 10 minutes of recovery $\left(F_{(3,17)}=1.8, P=0.13\right)$. See Figure $1 \mathrm{~B}$.

Experimental Gerontology, Vol. 48, No. 2 (February 2013): pg. 259-268. DOI. This article is (C) Elsevier and permission has been granted for this version to appear in e-Publications@Marquette. Elsevier does not grant permission for this article to be further copied/distributed or hosted elsewhere without the express permission from Elsevier. 


\section{EMG Activity during the Fatiguing Contraction}

Isometric Task The amplitude of the RMS EMG of both the biceps brachii and brachioradialis muscles increased during the fatiguing contraction (time effect, $P<0.001$ ). There was with no age difference for the biceps brachii (age effect, $F_{(1,19)}=0.05, P=0.79$ ) and brachioradialis $\left(F_{(1,19)}=0.34, P=0.57\right)$ and no interactions (Fig. $5 \mathrm{~A}$ shows the average of the biceps brachii and brachioradialis muscles). EMG activity of the triceps brachii increased during the isometric postural task (time effect, $F_{(2,18)}=57.0, P<0.001$ ) with no age difference (age effect, $F_{(1,19)}=0.13, P=0.72$ ) and no interactions. Coactivation did not change with fatigue $\left(F_{(2,18)}=2.03, P\right.$ $=0.82)$ and there was no age difference $\left(F_{(1,19)}=0.10, P=0.76\right)$.
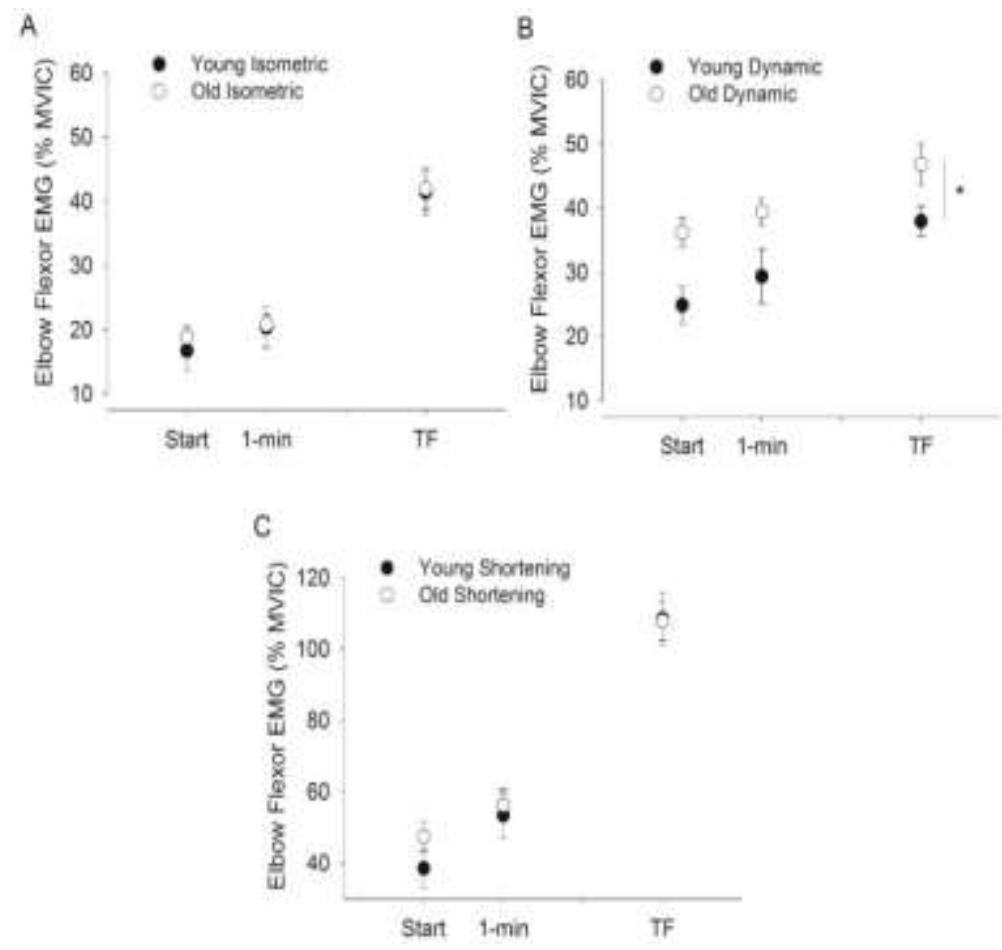

Figure 5. Root mean squared (RMS) EMG activity for the elbow flexors (biceps brachii and brachioradialis averaged) during the fatiguing contraction in young and old men

For all panels the mean EMG ( \pm SEM) is shown for values normalized to EMG during the MVIC (\% MVIC). A-B. EMG activity (\% MVIC) for the biceps brachii and brachioradialis (pooled) for the isometric (panel $A, n=7$ young and 14 old men) and dynamic tasks (panel $B, n=9$ young and 16 old men) during the fatiguing contraction. For both tasks EMG was analyzed over 15-s intervals at the beginning, 1 min and the end of the fatiguing task. For the dynamic task (B), $15 \mathrm{~s}$ involved 5 cycles of contractions (lifting and lowering). [* indicates an age difference at $\mathrm{P}<0.05$ ]. C.

Experimental Gerontology, Vol. 48, No. 2 (February 2013): pg. 259-268. DOI. This article is (C) Elsevier and permission has been granted for this version to appear in e-Publications@Marquette. Elsevier does not grant permission for this article to be further copied/distributed or hosted elsewhere without the express permission from Elsevier. 
EMG activity (\% MVIC) for the biceps brachii and brachioradialis (pooled) for the dynamic task during the shortening (lifting) phase only during the 5 contractions at each interval. In contrast to the when the 5 full cycles of data (15 s) there was no age difference in EMG during the lifting phase $(P>0.05)$. Note that $1 \mathrm{~min}$ is equivalent in time to $10.5 \%$ and $5.8 \%$ of time to failure in young and old men respectively for isometric task and $15.9 \%$ and $16.9 \%$ respectively for the dynamic task.

Dynamic Task EMG was examined during 5 dynamic contraction cycles (15 s so that the lifting, lowering and transition phases were included) at each time interval examined. EMG activity increased during the dynamic task for the biceps brachii (time effect, $F_{(2,22)}=$ 20.0, $P<0.001$ ) and brachioradialis muscles (time effect, $F_{(2,22)}=$ 5.50, $P=0.012$ ). The amplitude of the RMS EMG was greater for the old men during the dynamic fatiguing contraction for the biceps brachii (age effect, $F_{(1,23)}=4.46, P=0.046$ ) and brachioradialis muscle (age effect, $F_{(1,23)}=6.26, P=0.02$ ) with no interactions (Fig. 5B shows the average of the biceps brachii and brachioradialis muscle). Analysis of the RMS EMG of shortening or concentric (lifting) phase only during the 5 dynamic contraction cycles examined at each time interval, showed no age difference (Fig. 5C). The young and old men had similar EMG activity for the biceps brachii $\left(F_{(1,23)}=0.12, P=0.92\right)$ and brachioradialis muscles $\left(F_{(1,23)}=0.62, P=0.81\right)$.

Triceps brachii EMG activity was greater for old men than the young men (age effect, $F_{(1,23)}=4.63, P=0.04$ ) and increased during the fatiguing contractions (time effect, $F_{(2,22)}=13.5, P<0.001$ ) with no interactions. Coactivation (calculated over 15 seconds i.e. for 5 dynamic contraction cycles) did not change with fatigue $\left(F_{(2,22)}=1.45\right.$, $P=0.26)$ and there was no age difference $\left(F_{(1,23)}=0.03, P=0.87\right)$.

\section{Discussion}

This study investigated age-related differences in fatigability during and in recovery from a dynamic fatiguing contraction and an isometric postural fatiguing contraction performed with the elbow flexor muscles in men. The novel findings of this study were that for upper extremity muscles: (1) old men exhibited a similar time to failure as young men for a dynamic fatiguing task performed with a submaximal inertial load; (2) old men had a longer time to failure for the postural isometric task than the young while supporting a submaximal inertial load; (3) the time to task failure for both the

Experimental Gerontology, Vol. 48, No. 2 (February 2013): pg. 259-268. DOI. This article is (c) Elsevier and permission has been granted for this version to appear in e-Publications@Marquette. Elsevier does not grant permission for this article to be further copied/distributed or hosted elsewhere without the express permission from Elsevier. 
isometric postural and dynamic task were associated with the initial peak rates of relaxation of the muscle indicating muscle mechanisms contributed to the time to failure of both tasks; (4) the initial power was associated with the difference (reduction) in time to failure between the dynamic and postural isometric task; (5) supraspinal fatigue (indicated by the SIT amplitude elicited from cortical stimulation) increased similarly with age during the isometric and dynamic tasks, although recovery of SIT was associated with recovery of strength for old men but not the young, and (6) greater EMG activity for the old men during the dynamic fatiguing task (but not the isometric task) compared with the young, indicated that the older men activated greater proportions of their muscle during the dynamic contractions due to a less economic strategy in the non-lifting phase.

Despite similar self-reported physical activity levels for the young and old men in this study, at baseline, the age difference in power during elbow flexion (28.8\%) was twice that of maximal isometric strength (14.4\%). This greater age-related difference in power relative to maximal force has been widely reported for both upper and lower limb muscles (McNeil et al. 2007; Metter et al. 1997; Valour et al. 2003) and likely due to muscular mechanisms. First, drive to the motor cortex and corticomotor excitability (indicated by the SIT amplitude and the MEP respectively) during the maximal strength contraction at baseline was similar for the young and old men. Contractile relaxation (peak rates of relaxation) however, was slower for the old compared with young and this is consistent with many other studies of the upper and lower limb (Baudry et al. 2006; Callahan and Kent-Braun 2011; Dalton et al. 2010b; Doherty and Brown 1997; Hunter et al. 1999; Hunter et al. 2008; McNeil and Rice 2007; Valour et al. 2003). Furthermore, initial power was associated with peak rates of relaxation so that slower muscle had less maximal power with the 20\% MVC load. As seen in leg muscles (Reid and Fielding 2012), loss of power with age in the upper extremity may have functional implications for old adults.

A primary finding of this study was that the old men had similar fatigue to young men during a dynamic fatiguing task performed with the elbow flexor muscles. In contrast, the old men were able to sustain an isometric postural contraction with the same load twice as long with the elbow flexor muscles. The age-related fatigue resistance during the

Experimental Gerontology, Vol. 48, No. 2 (February 2013): pg. 259-268. DOI. This article is (C) Elsevier and permission has been granted for this version to appear in e-Publications@Marquette. Elsevier does not grant permission for this article to be further copied/distributed or hosted elsewhere without the express permission from Elsevier. 
isometric contraction has been observed before for lower limb muscles during postural isometric tasks using a compliant load during submaximal contraction (Griffith et al. 2010) and for isometric force tasks in both upper and lower limb muscles [see (Kent-Braun 2009)]. For the dynamic task, both age groups had a briefer time to failure with a relatively greater difference between isometric and dynamic tasks for the old men (64\% decline) than the young (37\%). Thus, in contrast to the isometric task, the age difference was diminished for the dynamic task. Our association data however showed that less powerful subjects (usually the old), exhibited the greatest difference in time to failure between the isometric and dynamic task. Muscle mechanisms (indicated by rates of relaxation data) that resulted in lower power and an altered strategy to complete the dynamic task (indicated by EMG results) were likely responsible for the large age difference between the duration of the isometric and dynamic tasks.

During the dynamic fatigue task, subjects were required to perform the contractions through the range of motion ( 1 cycle) once every $3 \mathrm{~s}$ (although they were not asked to contract as quickly as possible). Under these task requirements, subjects were able to select their speed of contraction and strategy during the dynamic task over the given time of $3 \mathrm{~s}$ for each cycle. When asked to contract as quickly as possible with a submaximal load, and at high velocities old adults were more fatigable than young for lower limb muscles (Callahan and Kent-Braun 2011; Dalton et al. 2012; 2010b). Young and old adults had similar fatigue however at slower speeds of contraction (Callahan et al. 2009; Dalton et al. 2012). The lack of age difference in fatigue during the dynamic contraction for the elbow flexor muscles suggests that the old adults chose a speed of contraction (not greater than 320 deg/s for old and $380 \mathrm{deg} / \mathrm{s}$ for young, see Table 1) that did not impair their ability to complete the task more than young. For the knee extensors, old men had greater fatigue over 30 contractions when the maximal velocity with a $20 \%$ load was $380 \mathrm{deg} / \mathrm{s}$ for the old adults and $\sim 480 \mathrm{deg} / \mathrm{s}$ for the young men (Dalton et al. 2012). Furthermore, at $270 \mathrm{deg} / \mathrm{s}$, fatigue of maximal torque with the knee extensor muscles was greater for old women than young women over 4 minutes (Callahan and Kent-Braun 2011). Despite the contraction velocity being greater for the elbow flexor than for knee extensor muscles at baseline (Callahan and Kent-Braun 2011), the elbow flexor muscles showed no age-related difference in fatigue or the time to

Experimental Gerontology, Vol. 48, No. 2 (February 2013): pg. 259-268. DOI. This article is (C) Elsevier and permission has been granted for this version to appear in e-Publications@Marquette. Elsevier does not grant permission for this article to be further copied/distributed or hosted elsewhere without the express permission from Elsevier. 
failure. Whether an age difference in fatigue of the elbow flexor muscles during dynamic contractions when the requirement is to contract the arm muscles as fast as possible in not known.

Despite the similar time to failure during the dynamic task, muscle activation (EMG activity) of the older men was greater than the young (start and finish when all phases of the dynamic contraction cycle were analyzed) but was similar for the age groups during the isometric task. As we expected, EMG activity increased during both contraction types and is likely due to an increase in motor unit recruitment and changes in discharge rates to compensate the decline in the force-generating capacity of the muscle fiber (Garland et al. 1994; Riley et al. 2008). During the isometric task, the EMG started and ended at similar levels (relative to MVIC) in the young and old adults but because of the longer time to failure with age, the rate of change in EMG was faster for young probably due a more fatigue resistant muscle in the old men as we have seen before (Yoon et al. 2012). In contrast, agonist muscle activation was greater for old men during the dynamic fatiguing contractions at the start and the end of the task when the entire cycle (lifting and lowering of the load) was quantified (see Fig. 5B). The increased activation was not due to coactivation of the antagonist muscle which did not differ with age during the dynamic contractions. Analysis of the lifting (shortening) phase only however, showed activation to be similar (see Fig. 5C). This comparison indicates that during each contraction cycle of the dynamic protocol, old adults adopted a less efficient strategy that involved greater activation during the non-lifting phase of the cycle (lengthening or transition phase) to achieve the dynamic task. This less efficient activation strategy that involved greater muscle activation and therefore greater metabolic cost likely led to increased rates of fatigue than when sustaining the isometric contraction.

Our data also provides evidence that muscular mechanisms contributed to the diminished age difference in time to failure for the dynamic task compared with the isometric postural contraction. First, peak rates of relaxation were associated with the time to failure indicating that a slower muscle led to a longer time to failure for both fatigue tasks. Lower peak rates of relaxation in old men compared with young indicate they have a slower muscle than young which is more fatigue resistant (Hunter et al. 1999; Klein et al. 2003; Monemi et al.

Experimental Gerontology, Vol. 48, No. 2 (February 2013): pg. 259-268. DOI. This article is (C) Elsevier and permission has been granted for this version to appear in e-Publications@Marquette. Elsevier does not grant permission for this article to be further copied/distributed or hosted elsewhere without the express permission from Elsevier. 
1998). Hence, slower muscle can be advantageous when the muscle is required to sustain a static position. However, the advantage is diminished when the requirement is to move the limb.

Second, although supraspinal fatigue (assessed as the superimposed twitch force with cortical stimulation) increased with both contractions for the young and old men, the increase was similar for the age groups when assessed during (at 1 minute) and immediately after the contraction. Few studies have examined supraspinal fatigue with transcranial magnetic stimulation in response to dynamic contractions (Goodall et al. 2012; Sidhu et al. 2009). These studies have only been conducted in the leg muscles with no studies involving older adults. Here we showed that in the absence of a progressively ischemic muscle which is often experienced during isometric contractions (Hunter et al. 2006; Rowell and O'Leary 1990), supraspinal fatigue during dynamic contractions was of similar magnitudes to that exhibited during and in recovery from sustained isometric contractions. There was however, no age difference in the supraspinal fatigue for the dynamic tasks. Hence, neural drive to the motor cortex was similarly reduced after the isometric and dynamic protocols and with aging in men.

Furthermore, corticomotor excitability changed similarly for the young and old adults because both the MEP and $M$ wave were similar for young and old men throughout both tasks. A decline in M-wave amplitude or area indicates a failure in the neuromuscular transmission and/or sarcolemmal excitability with fatigue (Fuglevand et al. 1993). The M-wave amplitude in biceps brachii muscle during the MVIC did not change with fatigue for both sessions. The MEP is influenced by the excitability of the motor cortex and the a-motorneurone pool (Taylor et al. 1999). The MEP size of elbow flexor muscles can increase during a sustained isometric contractions indicating an increase in excitability of neurons in the motor cortex (Taylor and Gandevia 2008). Similar to the M-wave, the MEP elicited during MVIC before, during, and after both fatiguing contractions did not change, suggesting the reduction in force was not related to the excitability of the motor cortex.

An important finding in this study was that the recovery of maximal strength was associated with the recovery of supraspinal fatigue for the old men but not the young men after both tasks.

Experimental Gerontology, Vol. 48, No. 2 (February 2013): pg. 259-268. DOI. This article is (C) Elsevier and permission has been granted for this version to appear in e-Publications@Marquette. Elsevier does not grant permission for this article to be further copied/distributed or hosted elsewhere without the express permission from Elsevier. 
Although recovery in strength was similar for the young and old men over the 10 minutes, the contributions from supraspinal sources were greater for the old men than the young for both tasks. These results corroborate findings of a delayed recovery from neural centers with advanced age after isometric fatiguing contractions (Dalton et al. 2010a; Hunter et al. 2008; Yoon et al. 2012; Yoon et al. 2008). Our findings also suggest that recovery of voluntary activation after a dynamic fatiguing contraction is impaired with advanced age. Because neural adaptations initially improve strength and fatigue resistance in response to repeated bouts of fatiguing dynamic exercise (strength or resistance training), these results suggest there is potential for large neural adaptations during neuromuscular rehabilitation that involve dynamic and isometric contractions in old adults.

In summary, this study demonstrated that the age-related fatigue observed for isometric contractions of the elbow flexor muscles was not exhibited during a dynamic fatiguing contraction. The mechanisms for the age difference between the two types of fatiguing contraction could be attributed to muscular mechanisms and greater muscle activity. Supraspinal fatigue however, contributed to the reduction in maximal isometric force generating capacity elicited by both the isometric and dynamic tasks in both young and old adults. Recovery of maximal strength involved the recovery of supraspinal fatigue among old men.

\section{Highlights}

- We examined age-related fatigue from maximal velocity dynamic contractions of arms muscles in men.

- Age-related fatigue resistance with a static contraction was diminished for a dynamic task.

- Muscular mechanisms explained the age-related differences in fatigue.

- Old men had less efficient muscle activation strategy during the dynamic fatigue task.

- Supraspinal fatigue contributed to the force reduction in recovery of fatigue for the old men.

Experimental Gerontology, Vol. 48, No. 2 (February 2013): pg. 259-268. DOI. This article is (C) Elsevier and permission has been granted for this version to appear in e-Publications@Marquette. Elsevier does not grant permission for this article to be further copied/distributed or hosted elsewhere without the express permission from Elsevier. 
NOT THE PUBLISHED VERSION; this is the author's final, peer-reviewed manuscript. The published version may be accessed by following the link in the citation at the bottom of the page.

\title{
Acknowledgments
}

This research was supported by a National Institute of Aging grant [R15AG30730] to SKH and the National Research Foundation of Korea Grant funded by the Korean government [NRF-2009-352-G00020] to TY.

\section{Abbreviations}

\author{
ANOVA Analysis of Variance \\ EMG Electromyography \\ MEP Motor evoked potential \\ $M_{\max } \quad$ Maximal $M$ wave \\ MVCC Maximal voluntary concentric contraction \\ MVIC Maximal voluntary isometric contraction \\ $M$ wave Compound muscle action potential \\ RPE Rating of perceived exertion \\ TMS Transcranial magnetic stimulation \\ SIT Superimposed twitch
}

Publisher's Disclaimer: This is a PDF file of an unedited manuscript that has been accepted for publication. As a service to our customers we are providing this early version of the manuscript. The manuscript will undergo copyediting, typesetting, and review of the resulting proof before it is published in its final citable form. Please note that during the production process errors may be discovered which could affect the content, and all legal disclaimers that apply to the journal pertain.

\section{References}

Allman BL, Rice CL. An age-related shift in the force-frequency relationship affects quadriceps fatigability in old adults. J Appl Physiol. 2004;96:1026-1032.

Allman BL, Rice CL. Neuromuscular fatigue and aging: central and peripheral factors. Muscle Nerve. 2002;25:785-796.

Avin KG, Frey Law LA. Age-related differences in muscle fatigue vary by contraction type: a meta-analysis. Phys Ther. 2011;91:1153-1165.

Experimental Gerontology, Vol. 48, No. 2 (February 2013): pg. 259-268. DOI. This article is (C) Elsevier and permission has been granted for this version to appear in e-Publications@Marquette. Elsevier does not grant permission for this article to be further copied/distributed or hosted elsewhere without the express permission from Elsevier. 
Baudry S, Klass M, Pasquet B, Duchateau J. Age-related fatigability of the ankle dorsiflexor muscles during concentric and eccentric contractions. Eur J Appl Physiol. 2006;100:515-525.

Callahan DM, Foulis SA, Kent-Braun JA. Age-related fatigue resistance in the knee extensor muscles is specific to contraction mode. Muscle Nerve. 2009;39:692-702.

Callahan DM, Kent-Braun JA. Effect of old age on human skeletal muscle force-velocity and fatigue properties. J Appl Physiol. $2011 ; 111: 1345-1352$.

Christie A, Snook EM, Kent-Braun JA. Systematic review and metaanalysis of skeletal muscle fatigue in old age. Med Sci Sports Exerc. 2011;43:568-577.

Dalton BH, Harwood B, Davidson AW, Rice CL. Recovery of motoneuron output is delayed in old men following highintensity fatigue. J Neurophysiol. 2010a;103:977-985.

Dalton $\mathrm{BH}$, Power GA, Vandervoort AA, Rice $\mathrm{CL}$. The age-related slowing of voluntary shortening velocity exacerbates power loss during repeated fast knee extensions. Exp Gerontol. 2012;47:85-92.

Dalton BH, Power GA, Vandervoort AA, Rice CL. Power loss is greater in old men than young men during fast plantar flexion contractions. J Appl Physiol. 2010b;109:1441-1447.

Doherty TJ, Brown WF. Age-related changes in the twitch contractile properties of human thenar motor units. J Appl Physiol. 1997;82:93-101.

Enoka RM, Duchateau J. Muscle fatigue: what, why and how it influences muscle function. The J Physiol. 2008;586:11-23.

Fuglevand AJ, Zackowski KM, Huey KA, Enoka RM. Impairment of neuromuscular propagation during human fatiguing contractions at submaximal forces. J Physiol. 1993;460:549-572.

Experimental Gerontology, Vol. 48, No. 2 (February 2013): pg. 259-268. DOI. This article is (c) Elsevier and permission has been granted for this version to appear in e-Publications@Marquette. Elsevier does not grant permission for this article to be further copied/distributed or hosted elsewhere without the express permission from Elsevier. 
NOT THE PUBLISHED VERSION; this is the author's final, peer-reviewed manuscript. The published version may be accessed by following the link in the citation at the bottom of the page.

Gandevia SC, Allen GM, Butler JE, Taylor JL. Supraspinal factors in human muscle fatigue: evidence for suboptimal output from the motor cortex. J Physiol. 1996;490:529-536.

Garland S, Enoka R, Serrano L, Robinson G. Behavior of motor units in human biceps brachii during a submaximal fatiguing contraction. J Appl Physiol. 1994;76:2411-2419.

Goodall S, Gonzalez-Alonso J, Ali L, Ross EZ, Romer LM. Supraspinal fatigue after normoxic and hypoxic exercise in humans. J Physiol. 2012;590:2767-82.

Griffith EE, Yoon T, Hunter SK. Age and load compliance alter time to task failure for a submaximal fatiguing contraction with the lower leg. J Appl Physiol. 2010;108:1510-1519.

Grimby G, Danneskiold-Samsoe B, Hvid K, Saltin B. Morphology and enzymatic capacity in arm and leg muscles in 78-81 year old men and women. Acta Physiol Scand. 1982;115:125-134.

Hermens H, Freriks L, Merletti R, Hägg G, Stegeman D, Blok J, Rau G, Disselhorst-Klug C. SENIAM 8: European Recommendations for Surface ElectroMyoGraphy. Roessingh Research and Development B.V; 2000.

Hess CW, Mills KR, Murray NM. Magnetic stimulation of the human brain: facilitation of motor responses by voluntary contraction of ipsilateral and contralateral muscles with additional observations on an amputee. Neurosci Lett. 1986;71:235-240.

Hunter SK. Aging and the mechanisms of task-dependent muscle fatigue. In: Shinohara M, editor. Advances in Neuromuscular Physiology of Motor Skills and Muscle Fatigue. Research Signpost; 2009.

Hunter SK, Rochette L, Critchlow A, Enoka RM. Time to task failure differs with load type when old adults perform a submaximal fatiguing contraction. Muscle Nerve. 2005;31:730-740.

Experimental Gerontology, Vol. 48, No. 2 (February 2013): pg. 259-268. DOI. This article is (C) Elsevier and permission has been granted for this version to appear in e-Publications@Marquette. Elsevier does not grant permission for this article to be further copied/distributed or hosted elsewhere without the express permission from Elsevier. 
Hunter SK, Ryan DL, Ortega JD, Enoka RM. Task differences with the same load torque alter the endurance time of submaximal fatiguing contractions in humans. J Neurophysiol. 2002;88:3087-3096.

Hunter SK, Schletty JM, Schlachter KM, Griffith EE, Polichnowski AJ, Ng AV. Active hyperemia and vascular conductance differ between men and women for an isometric fatiguing contraction. J Appl Physiol. 2006;101:140-150.

Hunter SK, Thompson MW, Adams RD. Relationships among ageassociated strength changes and physical activity level, limb dominance, and muscle group in women. J Gerontol Sci. 2000;55:B264-273.

Hunter SK, Thompson MW, Ruell PA, Harmer AR, Thom JM, Gwinn TH, Adams RD. Human skeletal sarcoplasmic reticulum $\mathrm{Ca} 2+$ uptake and muscle function with aging and strength training. J Appl Physiol. 1999;86:1858-1865.

Hunter SK, Todd G, Butler JE, Gandevia SC, Taylor JL. Recovery from supraspinal fatigue is slowed in old adults after fatiguing maximal isometric contractions. J Appl Physiol. 2008;105:11991209.

Kent-Braun JA. Skeletal muscle fatigue in old age: whose advantage? Exer Sport Sci Rev. 2009;37:3-9.

Klein CS, Marsh GD, Petrella RJ, Rice CL. Muscle fiber number in the biceps brachii muscle of young and old men. Muscle Nerve. 2003;28:62-68.

Kriska AM, Bennett PH. An epidemiological perspective of the relationship between physical activity and NIDDM: from activity assessment to intervention. Diabetes/metabolism Rev. 1992;8:355-372.

Laforest S, St-Pierre DM, Cyr J, Gayton D. Effects of age and regular exercise on muscle strength and endurance. Eur J Appl Physiol. 1990;60:104-111.

Experimental Gerontology, Vol. 48, No. 2 (February 2013): pg. 259-268. DOI. This article is (C) Elsevier and permission has been granted for this version to appear in e-Publications@Marquette. Elsevier does not grant permission for this article to be further copied/distributed or hosted elsewhere without the express permission from Elsevier. 
NOT THE PUBLISHED VERSION; this is the author's final, peer-reviewed manuscript. The published version may be accessed by following the link in the citation at the bottom of the page.

Lanza IR, Russ DW, Kent-Braun JA. Age-related enhancement of fatigue resistance is evident in men during both isometric and dynamic tasks. J Appl Physiol. 2004;97:967-975.

Lindstrom B, Lexell J, Gerdle B, Downham D. Skeletal muscle fatigue and endurance in young and old men and women. J Gerontol. 1997;52:B59-66.

McNeil CJ, Rice CL. Fatigability is increased with age during velocitydependent contractions of the dorsiflexors. J Gerontol. 2007;62A:624-629.

McNeil CJ, Vandervoort AA, Rice CL. Peripheral impairments cause a progressive age-related loss of strength and velocity-dependent power in the dorsiflexors. J Appl Physiol. 2007;102:1962-8.

Metter EJ, Conwit R, Tobin J, Fozard JL. Age-associated loss of power and strength in the upper extremities in women and men. J Gerontol. 1997;52:B267-276.

Metter EJ, Talbot LA, Schrager M, Conwit RA. Arm-cranking muscle power and arm isometric muscle strength are independent predictors of all-cause mortality in men. J Appl Physiol. 2004;96:814-821.

Monemi M, Eriksson PO, Eriksson A, Thornell LE. Adverse changes in fibre type composition of the human masseter versus biceps brachii muscle during aging. J Neurol Sci. 1998;154:35-48.

Oldfield RC. The assessment and analysis of handedness: the Edinburgh Inventory. Neuropsychologia. 1971;9:97-113.

Petrella JK, Kim JS, Tuggle SC, Hall SR, Bamman MM. Age differences in knee extension power, contractile velocity, and fatigability. J Appl Physiol. 2005;98:211-220.

Reid KF, Fielding RA. Skeletal muscle power: a critical determinant of physical functioning in older adults. Exer Sport Sci Rev. 2012;40:4-12.

Experimental Gerontology, Vol. 48, No. 2 (February 2013): pg. 259-268. DOI. This article is (C) Elsevier and permission has been granted for this version to appear in e-Publications@Marquette. Elsevier does not grant permission for this article to be further copied/distributed or hosted elsewhere without the express permission from Elsevier. 
NOT THE PUBLISHED VERSION; this is the author's final, peer-reviewed manuscript. The published version may be

Riley ZA, Maerz AH, Litsey JC, Enoka RM. Motor unit recruitment in human biceps brachii during sustained voluntary contractions. J Physiol. 2008;586:2183-2193.

Rowell LB, O'Leary DS. Reflex control of the circulation during exercise: chemoreflexes and mechanoreflexes. J Appl Physiol. 1990;69:407-418.

Sidhu SK, Bentley DJ, Carroll TJ. Locomotor exercise induces longlasting impairments in the capacity of the human motor cortex to voluntarily activate knee extensor muscles. J Appl Physiol. 2009; 106:556-565.

Taylor JL, Butler JE, Gandevia SC. Altered responses of human elbow flexors to peripheral-nerve and cortical stimulation during a sustained maximal voluntary contraction. Exp Brain Res. $1999 ; 27: 108-115$.

Taylor JL, Gandevia SC. A comparison of central aspects of fatigue in submaximal and maximal voluntary contractions. J Appl Physiol. 2008; 104:542-550.

Todd G, Taylor JL, Butler JE, Martin PG, Gorman RB, Gandevia S. Use of motor cortex stimulation to measure simultaneously the changes in dynamic muscle properties and voluntary activation in human muscles. J Appl Physiol. 2007;102:1756-1766.

Todd G, Taylor JL, Gandevia SC. Measurement of voluntary activation of fresh and fatigued human muscles using transcranial magnetic stimulation. J Physiol. 2003;551:661-671.

Todd G, Taylor JL, Gandevia SC. Reproducible measurement of voluntary activation of human elbow flexors with motor cortical stimulation. J Appl Physiol. 2004;97:236-242.

Valour D, Ochala J, Ballay $\mathrm{Y}$, Pousson M. The influence of ageing on the force-velocity-power characteristics of human elbow flexor muscles. Exp Gerontol. 2003;38:387-395.

Experimental Gerontology, Vol. 48, No. 2 (February 2013): pg. 259-268. DOI. This article is (C) Elsevier and permission has been granted for this version to appear in e-Publications@Marquette. Elsevier does not grant permission for this article to be further copied/distributed or hosted elsewhere without the express permission from Elsevier. 
NOT THE PUBLISHED VERSION; this is the author's final, peer-reviewed manuscript. The published version may be accessed by following the link in the citation at the bottom of the page.

Yoon T, Schlinder-Delap B, Keller ML, Hunter SK. Supraspinal fatigue impedes recovery from a low-intensity sustained contraction in old adults. J Appl Physiol. 2012;112:849-858.

Yoon T, Schlinder Delap B, Griffith EE, Hunter SK. Age-related muscle fatigue after a low-force fatiguing contraction is explained by central fatigue. Muscle Nerve. 2008;37:457-466. 